\title{
Isoprene Production on Enzymatic Hydrolysate of Peanut Hull Using Different Pretreatment Methods
}

\author{
Sumeng Wang, ${ }^{1}$ Ruichao Li, ${ }^{1}$ Xiaohua Yi, ${ }^{1}$ Tigao Fang, \\ Jianming Yang, ${ }^{1}$ and Hyeun-Jong $\mathrm{Bae}^{2}$ \\ ${ }^{1}$ Key Lab of Plant Biotechnology in Universities of Shandong Province, College of Life Sciences, \\ Qingdao Agricultural University, Qingdao 266109, China \\ ${ }^{2}$ Bio-Energy Research Institute, Chonnam National University, Gwangju 500-757, Republic of Korea \\ Correspondence should be addressed to Jianming Yang; yjming888@126.com and Hyeun-Jong Bae; baehj@chonnam.ac.kr
}

Received 21 June 2016; Revised 4 August 2016; Accepted 18 August 2016

Academic Editor: Liandong Zhu

Copyright (C) 2016 Sumeng Wang et al. This is an open access article distributed under the Creative Commons Attribution License, which permits unrestricted use, distribution, and reproduction in any medium, provided the original work is properly cited.

\begin{abstract}
The present study is about the use of peanut hull for isoprene production. In this study, two pretreatment methods, hydrogen peroxide-acetic acid (HPAC) and popping, were employed prior to enzymatic hydrolysis, which could destroy the lignocellulosic structure and accordingly improve the efficiency of enzymatic hydrolysis. It is proven that the isoprene production on enzymatic hydrolysate with HPAC pretreatment is about 1.9-fold higher than that of popping pretreatment. Moreover, through High Performance Liquid Chromatography (HPLC) analysis, the amount and category of inhibitors such as formic acid, acetic acid, and HMF were assayed and were varied in different enzymatic hydrolysates, which may be the reason leading to a decrease in isoprene production during fermentation. To further increase the isoprene yield, the enzymatic hydrolysate of HPAC was detoxified by activated carbon. As a result, using the detoxified enzymatic hydrolysate as the carbon source, the engineered strain YJM21 could accumulate $297.5 \mathrm{mg} / \mathrm{L}$ isoprene, which accounted for about $90 \%$ of isoprene production by YJM21 fermented on pure glucose $(338.6 \mathrm{mg} / \mathrm{L})$. This work is thought to be the first attempt on isoprene production by E. coli using peanut hull as the feedstock. More importantly, it also shows the prospect of peanut hull to be considered as an alternative feedstock for bio-based chemicals or biofuels production due to its easy access and high polysaccharide content.
\end{abstract}

\section{Introduction}

Isoprene (2-methylbuta-1,3-diene), as a polymer building block, plays a pertinent role in the synthetic chemistry industry and represents an important biological material. Isoprene could serve as the feedstock not only in industrial production of synthetic rubber or aviation fuel $[1,2]$ but also in the fields of isoprenoid medicines and fragrances [3]. Currently, industrial isoprene production mainly relies on fossil sources, achieved by means of chemical synthesis techniques $[1,4]$. However, due to the decrease of petroleum reserve and the enhancement of environmental awareness, it becomes increasingly urgent and necessary to produce isoprene using renewable resources as an alternative to petroleum resource.

Although isoprene could be produced from many kinds of plants [5] or some microorganisms such as fungi, Eurotium amstelodami [6], both ways still sound impractical, since it is difficult to harvest isoprene from plant species [7], and the material shortage and low conversion efficiency are widely recognized as a bottleneck for isoprene production by microorganisms.

Today, millions of tons of agricultural lignocellulosic wastes are produced around the world annually. The abundant supply and low cost properties $[8,9]$ have made agricultural lignocellulosic wastes the most promising materials for substituting the dwindling fossil fuels. In China, the annual production of peanut could reach up to $1.3 \times 10^{7}$ tons, which accordingly resulted in $3.64 \times 10^{6}$ tons of peanut hull in 2008 [10]. Recently, the USDA reported that peanut production in China accounted for approximately $45 \%$ of the total yield of the world's peanut [11] (USDA 2015). As is shown in Figure 1, peanut hull consists of $46.8 \%$ holocellulose, $5.8 \%$ ash, $4.0 \%$ 


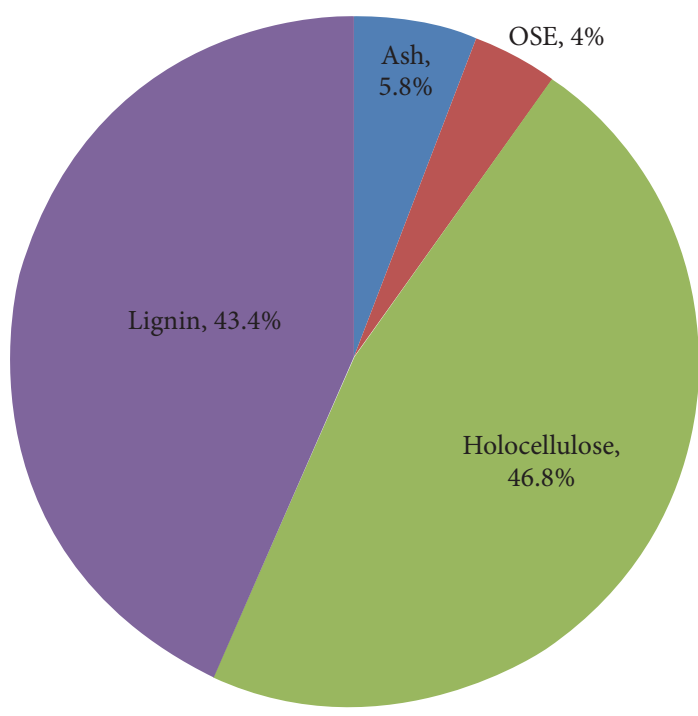

FIgURE 1: Chemical composition of peanut hull.

OSE, and 43.4\% Klason lignin. Its high polysaccharide content makes peanut hull a suitable feedstock for the production of bio-based chemicals or biofuels including isoprene.

Since cellulose is usually surrounded by hemicellulose and lignin which would reduce the conversion rate of cellulose into fermentable sugar, it is vital to develop an economic pretreatment method to change the lignocellulosic biomass structure so as to improve degradation efficiency by cellulase to translate cellulose into fermentative saccharides. So far, various pretreatment techniques have been developed to disrupt the lignocellulosic structure prior to enzyme hydrolysis, including dilute acid, steam explosion, liquid hot water, ammonia pretreatments, and popping [12, 13]. Among them, the machine used in popping pretreatment is a very simple system consisting of direct burner and rotary reactor without steam generator [12], and this process has remarkable advantages including higher saccharification efficiency, cost effectiveness, and environmental safety [14]. Acetic acid might enhance the hydrolysis efficiency of hemicellulose [15], and hydrogen peroxide pretreatment has many advantages such as forming fewer inhibitors and generating more glucose yield in addition to lower toxicity and less environmental impact $[15,16]$.

Based on the above analysis, in this study, we introduced two pretreatment methods to treat peanut hull prior to hydrolysis by cellulase, popping [17] and HPAC [18], with HPAC being an efficient method, including hydrogen peroxide and acetic acid. Meanwhile, to further enhance the isoprene production, we detoxified the enzymatic hydrolysate of peanut hull pretreated by HPAC. We finally achieved the different isoprene production with several kinds of enzymatic hydrolysates. This work is the first attempt to produce isoprene by $E$. coli using the peanut hull as the feedstock. And, more importantly, this work provides evidence to show that another lignocellulose material, peanut hull, could be considered as a promising feedstock for industrial production of bio-based chemicals or biofuels.

\section{Materials and Methods}

2.1. HPAC Pretreatment and Popping Pretreatment. Peanut hull $(\mathrm{PH})$ used in this experiment was collected from Shandong province, China. $\mathrm{PH}$ was milled and screened to a 40-60 mesh size and then was air-dried after its associated wastes were washed by running water. To be specific, tengram peanut hulls (PHs) were treated with $100 \mathrm{~mL}$ of HPAC solution, a mixture of hydrogen peroxide and acetic acid $(1: 1$; $\mathrm{v} / \mathrm{v}$ ), and then incubated at $80^{\circ} \mathrm{C}$ for $3 \mathrm{~h}$, after which materials were filtered to separate the HPAC solution from the solid residue, and they were washed 3 times by running water until neutral $\mathrm{pH}$ was reached [18].

A total of $100 \mathrm{~g}$ (dry weight) of PHs was treated using the popping equipment [17]. Filled with PHs (moisture content: $75 \%$ ), the reactor was directly heated with a gas burner at a rate between 15 and $20^{\circ} \mathrm{C} / \mathrm{min}$ and rapidly opened the hatch at $220^{\circ} \mathrm{C}$ and $1.47 \mathrm{MPa}$. After treatment, materials were recovered in a reactor and cooled at room temperature. And then HPAC and popping treated PHs were dried by a lyophilizer at $-45^{\circ} \mathrm{C}$ for 5 days.

2.2. SEM Imaging. The surface morphologies of samples, including pretreated PHs by popping and HPAC and untreated $\mathrm{PH}$, were analyzed using scanning election microscopy (SEM; JSM-7500F, Jeol, Japan). Imaging was captured at a beam voltage of $4 \mathrm{kV}$. Prior to observation and photography, biomass samples were dried at $50^{\circ} \mathrm{C}$ for $24 \mathrm{~h}$ and gold sputter-coated $(20 \mathrm{~nm})$.

2.3. Chemical Composition Analysis. Both $20 \mathrm{mg}$ raw and pretreated $\mathrm{PHs}$ were used to analyze chemical composition. The structural carbohydrates, ash, and lignin analysis procedure of all biomass samples were measured according to the NREL Laboratory Analytical Procedure (LAP) [19]. And organic solvent extractives (OSE) were analyzed with TAPPI Standard Methods [20]. The raw and pretreated (HPAC and popping) $\mathrm{PHs}$ were analyzed for their neutral sugar content using gas chromatography (GC) [13]. The samples were analyzed via GC (GC-2010; Shimadzu, Otsu, Japan) using a DB-225 capillary column $(30 \mathrm{~m} \times 0.25 \mathrm{~mm}$ i.d., $0.25 \mu \mathrm{m}$ film thickness, J\&W; Agilent, Folsom, CA, USA) operated with helium. The operating conditions were as follows: injector temperature of $220^{\circ} \mathrm{C}$, flame ionization detector (FID) at $250^{\circ} \mathrm{C}$, and an oven temperature of $100^{\circ} \mathrm{C}$ for $1.5 \mathrm{~min}$ with a constant increase of $5^{\circ} \mathrm{C} / \mathrm{min}$ to $220^{\circ} \mathrm{C}$.

2.4. Enzymatic Hydrolysis. The PHs as $1 \%$ (w/v) substrate were treated in $50 \mathrm{mM}$ sodium citrate buffer ( $\mathrm{pH} 4.8$ ) supplemented with $0.01 \%(\mathrm{w} / \mathrm{v})$ sodium azide. Each of the enzymes, celluclast (Novozymes, Denmark) and xylanase (endo-1,4- $\beta$ xylanase from Trichoderma longibrachiatum, Sigma-Aldrich, USA), were loaded with 30 FPU per gram of glucan and 300 international units $(\mathrm{IU}) / \mathrm{mL}$, respectively. All samples were completely suspended in rotary shaker at $200 \mathrm{rpm}$ at $37^{\circ} \mathrm{C}$ for $48 \mathrm{~h}$. All enzymatic hydrolysis experiments were performed in triplicate. 
2.5. Detoxification with Activated Carbon. The enzymatic hydrolysate of peanut hull (HPAC pretreated) along with $1 \%(\mathrm{w} / \mathrm{v})$ activated carbon (05-690A, 50-200 mesh, Fisher Scientific Co., Pittsburgh, PA, USA) was mixed in $250 \mathrm{~mL}$ flask. And then the flask had been incubating at $30^{\circ} \mathrm{C}$ with shaking at the rate of $180 \mathrm{rpm}$ for $10 \mathrm{~h}$. After treatment, the activated carbon was removed from the mixture by centrifugation at $10000 \mathrm{rpm}$ for $10 \mathrm{~min}$. To get the detoxification hydrolysate, the supernate was finally filtered by using $0.2 \mu \mathrm{m}$ filter membrane.

2.6. Shake Flask Fermentation. Shake flask experiments were carried out in triplicate using a series of $25 \mathrm{~mL}$ sealed shake flasks containing $5 \mathrm{~mL}$ fermentation medium including glucose $2 \mathrm{~g} / \mathrm{L}$ or suitable concentration of enzymatic hydrolysate, $\mathrm{K}_{2} \mathrm{HPO}_{4} 9.8 \mathrm{~g} / \mathrm{L}$, beef extract $9 \mathrm{~g} / \mathrm{L}$, ferric ammonium citrate $0.3 \mathrm{~g} / \mathrm{L}$, citric acid monohydrate $2.1 \mathrm{~g} / \mathrm{L}$, $\mathrm{MgSO}_{4} 0.06 \mathrm{~g} / \mathrm{L}$, and $1 \mathrm{~mL}$ trace element solution, consisting of $\left(\mathrm{NH}_{4}\right)_{6} \mathrm{Mo}_{7} \mathrm{O}_{24} \cdot 4 \mathrm{H}_{2} \mathrm{O} \quad 0.37 \mathrm{~g} / \mathrm{L}, \mathrm{ZnSO}_{4} \cdot 7 \mathrm{H}_{2} \mathrm{O} \quad 0.29 \mathrm{~g} / \mathrm{L}$, $\mathrm{H}_{3} \mathrm{BO}_{4} 2.47 \mathrm{~g} / \mathrm{L}, \mathrm{CuSO}_{4} \cdot 5 \mathrm{H}_{2} \mathrm{O} 0.25 \mathrm{~g} / \mathrm{L}$, and $\mathrm{MnCl}_{2} \cdot 4 \mathrm{H}_{2} \mathrm{O}$ $1.58 \mathrm{~g} / \mathrm{L}$. Meanwhile, the medium contained $34 \mathrm{mg} / \mathrm{mL} \mathrm{Cm}$ and $100 \mathrm{mg} / \mathrm{mL}$ Amp. The engineered E. coli strain YJM21 [21] was inoculated to the culture broth and incubated in a gyratory shaker incubator at $37^{\circ} \mathrm{C}$ and $180 \mathrm{rpm}$. When $\mathrm{OD}_{600}$ reached 0.6 , IPTG was added in final concentration of $0.5 \mathrm{mM}$, and the culture was further incubated at $30^{\circ} \mathrm{C}$ for $24 \mathrm{~h}$.

2.7. Analytical Methods. Bacterial growth conditions were estimated from the optical density (OD) of the medium with a spectrophotometer (UV2310II, Shanghai Precision \& Scientific Instrument Co., Ltd., China) at a wavelength of $600 \mathrm{~nm}$. The concentration of isoprene was analyzed by a gas chromatograph (GC) equipped with a flame ionization detector (FID) and a TM-WAX column $(25 \mathrm{~m} \times 0.25 \mathrm{~mm}$ $\times 0.25 \mu \mathrm{m}) . \mathrm{N}_{2}$ was used as carrier gas. The initial column temperature was $50^{\circ} \mathrm{C}$ for $1 \mathrm{~min}$ and was increased at a rate of $6^{\circ} \mathrm{C} / \mathrm{min}$ to a final temperature of $80^{\circ} \mathrm{C}$, while the injector temperature was $140^{\circ} \mathrm{C}$ and the detector temperature was $230^{\circ} \mathrm{C}$, respectively.

To identify bacterial isoprene production, peak retention times and mass spectra were compared with those of the standard. Concentrations of isoprene produced by bacterial cells were calculated by converting GC peak area to $\mathrm{mg}$ of isoprene via a calibration curve. Isoprene standard (TCI-EP, Tokyo, Japan) of various concentrations was added to $600 \mathrm{~mL}$ fermentation medium to construct a calibration curve.

\section{Results and Discussion}

3.1. Chemical Composition and Monosugar Composition Rate of Peanut Hull. In China, peanut hull, considered as the agricultural waste, was redundant and was not utilized very well. Meanwhile, its high polysaccharide content makes it a suitable feedstock for the production of bio-based chemicals or biofuels including isoprene. Figure 1 enumerates the chemical compositions of the peanut hull, such as ash, organic solvent extractives (OSE), holocellulose (glucose, xylose, arabinose,

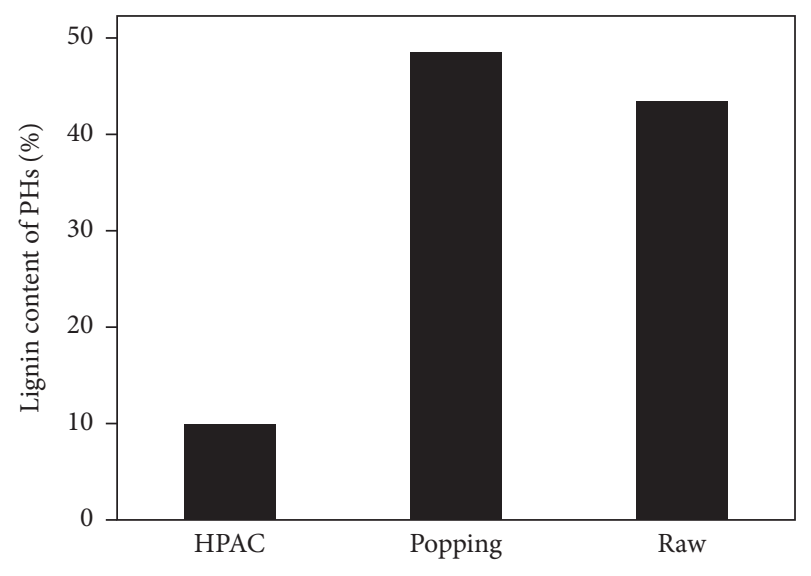

FIGURE 2: Lignin content of raw, popping, and HPAC pretreated PH.

galactose, rhamnose, and mannose), and Klason lignin. The $\mathrm{PH}$ content contained $46.8 \%$ holocellulose, $5.8 \%$ ash, $4.0 \%$ OSE, and $43.4 \%$ Klason lignin. Although the lignin content of peanut hull was high and peanut hull also had significant amount of available sugars for bioconversion, this result still indicated that the lignin of PH sample needed to be removed via pretreatment process to enhance the enzymatic hydrolysis efficiency. Thus, two pretreatment methods (popping and HPAC) were conducted and the efficiency of lignin removed was evaluated. Figure 2 had shown the difference of lignin content between raw $\mathrm{PH}$ and pretreated $\mathrm{PH}$. Compared with raw $\mathrm{PH}$, the lignin content of $\mathrm{PH}$ pretreated by HPAC was reduced about $77.3 \%$, while the lignin content of $\mathrm{PH}$ pretreated by popping was similar to raw $\mathrm{PH}$. What is more, the recovery dry mass yield of each of the pretreated samples (popping and HPAC) was approximately $75.9 \%$ and $49.3 \%$, respectively.

The monosugar contents of different pretreated $\mathrm{PH}$ were determined using GC (Figure 3). PH was mainly composed of $46.8 \%$ carbohydrates. In these carbohydrates, xylose and glucose were major components of sugar in raw $\mathrm{PH}$, comprising approximately $14.5 \%$ and $26.6 \%$ of dry mass, respectively. After pretreatment, in comparison with raw $\mathrm{PH}$, total carbohydrates of popping and HPAC PH were relatively increased about $1.6 \%$ and $27.3 \%$, respectively. Some monosugar content was relatively reduced when compared with raw $\mathrm{PH}$, but glucose content was significantly increased approximately 2 times in HPAC PH. Sugar (glucose) yield of each of the samples (popping and HPAC) was approximately $95.9 \%$ and $98.8 \%$, respectively. It was safe to reach a conclusion that the HPAC pretreatment was more effective than the popping pretreatment to increase the sugar content in the hydrolysate.

3.2. Surface Morphology of Pretreated Peanut Hull. The hydrolysis efficiency is directly related to the contact between cellulase and cellulose. To investigate the $\mathrm{PH}$ physical changes before and after pretreatment, the physical structures of them were studied with SEM (Figure 4). In comparison with the smooth and integrated surface of raw PH (Figure 4(a)), pores were present in the pretreated PH (Figure $4(\mathrm{~b})$ ) on 


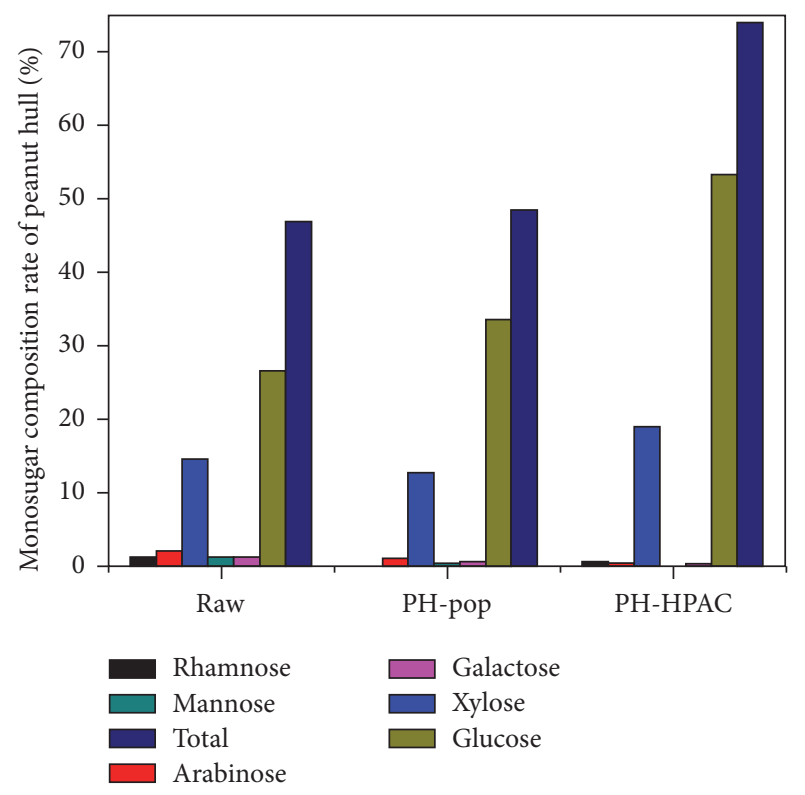

FIgURE 3: The monosugar contents of different pretreated PHs were determined using GC.

account of the high temperature and releasing the high pressure quickly, so that the structure of the $\mathrm{PH}$ was broken down. Figure 4(c) showed that the structure morphology of the HPAC pretreated PH was loosened and distortional, and the removed lignin might be viewed as the reason for the structure changes. No matter how destroyed the structure was or how removed the lignin was from $\mathrm{PH}$, the surface area connecting cellulose and cellulose was increased. Consequently, the enzymatic hydrolysis efficiency might be increased dramatically with popping pretreatment and HPAC pretreatment.

\subsection{Effect of Different Pretreated Methods of Peanut Hull on} Isoprene Production. In our previous studies [4, 21, 22], we have engineered $E$. coli strains to biosynthesize isoprene using native MEP and exogenous MVA pathway. Compared with other studies, we found that the engineered E. coli strain is more effective to produce isoprene than other engineered strains such as Cyanobacterium Synechocystis [2], Bacillus subtilis [23], and Saccharomyces cerevisiae [24]. Hence, in this paper, we also choose the E. coli strain to evaluate the enzymatic hydrolysates of pretreated peanut hull.

Two pretreatment methods, popping and HPAC, were found to be able to destroy the lignocellulosic structure, which accordingly enhanced hydrolysis efficiency by cellulase. To ascertain the extent to which isoprene production could be influenced by these two pretreatment methods, the engineered strain was cultured in a fermentation medium with three kinds of carbon sources including pure glucose and two types of enzymatic hydrolysates using HPAC pretreatment and popping pretreatment, respectively. As was shown in Figure 5, the titer of isoprene produced by pure glucose (HPAC pretreatment and popping pretreatment) reached $338.6 \mathrm{mg} / \mathrm{L}, 211 \mathrm{mg} / \mathrm{L}$, and $113.7 \mathrm{mg} / \mathrm{L}$, respectively.
The results demonstrated that the isoprene production from pure glucose fermentation was about 1.6 times and 3 times higher than that from HPAC and popping pretreatments, respectively, and using HPAC pretreatment cultures could produce approximately 1.9 times more isoprene production compared to using the popping pretreatment, with all the other conditions being the same.

Since lignocellulosic feedstocks mainly consist of cellulose, hemicellulose, and lignin [25], inhibitors exist in raw material and would be released during the course of pretreatment [26]. In addition, the concentration of inhibitors relied on the types of lignocellulosic feedstock and the different pretreatment methods utilized [26, 27]. Consequently, in this work, the reason leading to the significant difference in isoprene production among the three kinds of carbon sources would lie in the fact that inhibitors existed in two types of hydrolysates obtained by the HPAC and popping methods.

In this paper, to determine the categories and concentrations of inhibitors which were formed by HPAC and popping methods, two kinds of enzymatic hydrolysates were detected using HPLC method. Table 1 showed that there are four kinds of inhibitors (formic acid, acetic acid, hydroxymethylfurfural (HMF), and furfural) in the enzymatic hydrolysates with popping pretreatment, while only three kinds of inhibitors (acetic acid, furfural, and HMF) were measured in the enzymatic hydrolysate with HPAC pretreatment. Table 1 also notably indicated that the concentrations of acetic acid were approximated in two kinds of fermentation medium.

Different inhibitors have different detrimental effect on the cell growth and accordingly result in decrease in the yield of target product. Weak acid, such as formic acid and acetic acid, could cross the cell membrane, which resulted in the lower cell $\mathrm{pH}$ than normal and consequently inhibited cell growth [28, 29]. Mills et al. had also reported that formic acid had higher toxicity to E. coli than acetic acid [30]. Like furfural, HMF had a detrimental effect on DNA and would lead to single-strand breaks [29,30]. Meanwhile, Martinez et al. had proven that the minimal inhibitory concentrations of furfural and HMF would attain $3.5 \mathrm{mg} / \mathrm{mL}$ and $4.0 \mathrm{mg} / \mathrm{mL}$, respectively [31]. Thus, although the concentrations of HMF and furfural produced by popping pretreatment were higher than those of HPAC pretreatment, they were still too low to produce a significant impact on isoprene production.

Therefore, based on the above discussion, it can be concluded that formic acid in enzymatic hydrolysate of popping pretreatment would be the dominant factor for lower isoprene production. Additionally, acetic acid existed in HPAC hydrolysis which resulted in lower isoprene production by HPAC pretreatment than that by pure glucose.

\subsection{Detoxification Effect of Enzymatic Hydrolysate of HPAC} $\mathrm{PH}$ on Isoprene Production. To further enhance the production of isoprene, it is essential to remove inhibitors from enzymatic hydrolysate by using a proper method. Among various detoxification methods, activated charcoal claims the advantage of being cost effective and possessing higher capacity to absorb compounds, especially lignin-derived inhibitors and acetic acid, without affecting levels of sugar in 


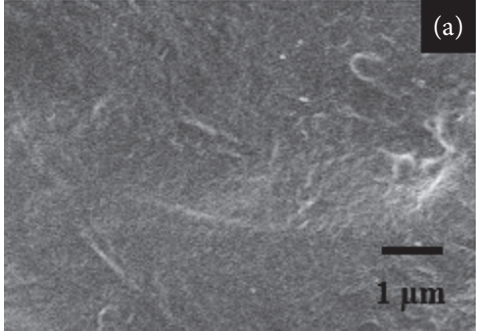

(a)

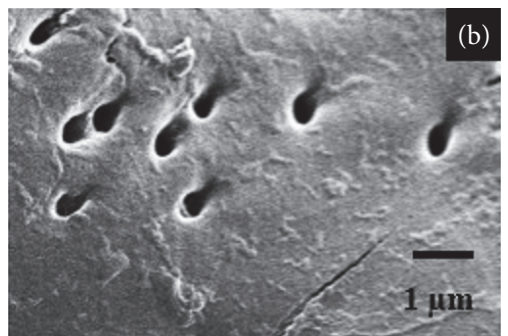

(b)

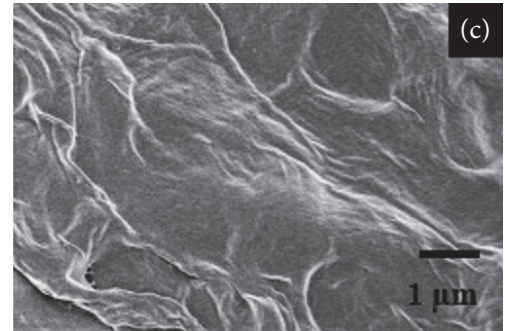

(c)

FIGURE 4: SEM images for raw (a), popping (b), and HPAC (c) pretreated PH.

TABLE 1: The types and concentrations of inhibitors in different fermentation medium.

\begin{tabular}{lccc}
\hline Concentration $(\mathrm{mg} / \mathrm{mL})$ & HPAC (detoxified hydrolysate) & HPAC (raw hydrolysate) & Popping \\
\hline Formic acid & 0 & 0 & 0.2445 \\
Acetic acid & 0.004 & 0.01775 & 0.0229 \\
HMF & $1.18 \times 10^{-5}$ & $4.36 \times 10^{-5}$ & 0.0119 \\
Furfural & $2.15 \times 10^{-5}$ & $1.01 \times 10^{-4}$ & $1.42 \times 10^{-3}$ \\
\hline
\end{tabular}

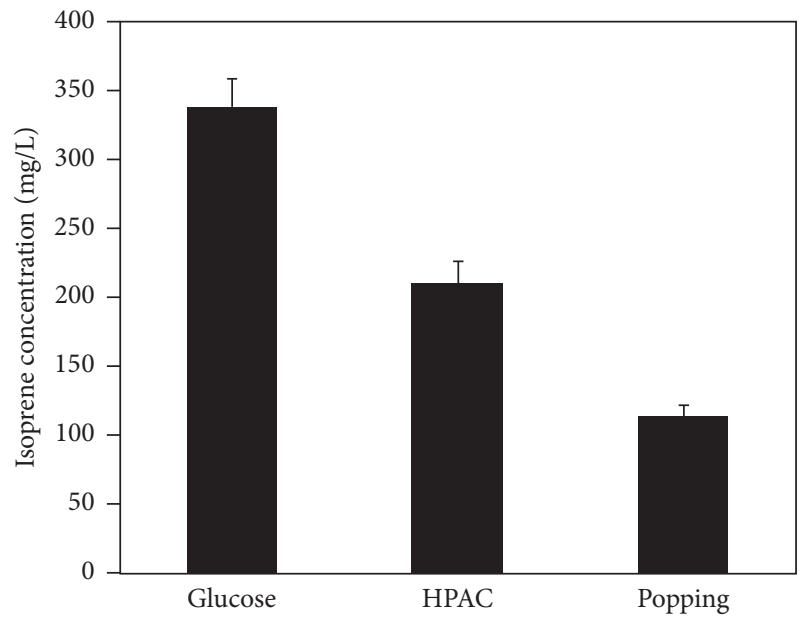

FIGURE 5: Effect of carbon sources on isoprene production. The engineered strain cultured in three different carbon sources including pure glucose, HPAC, and popping enzymatic hydrolysates. The cells were induced when $\mathrm{OD}_{600}$ reached about 0.6. The experiment was performed in triplicate.

hydrolysate $[13,32,33]$. In addition, it is safe and easy to be manipulated using activated carbon.

After the HPAC pretreated hydrolysate was detoxified with activated charcoal, fermentation was performed with detoxification hydrolysate and raw hydrolysate, respectively. As was seen in Figure 6, the isoprene production of detoxification of HPAC hydrolysate reached $297.5 \mathrm{mg} / \mathrm{L}$, with an increase of up to $41 \%$ compared with raw hydrolysate without detoxification. Based on the data shown in Table 1, through detoxification with activated charcoal, the concentrations of acetic acid, HMF, and furfural were reduced by $76.90 \%$, $72.83 \%$, and $78.77 \%$, respectively. The results indicated that

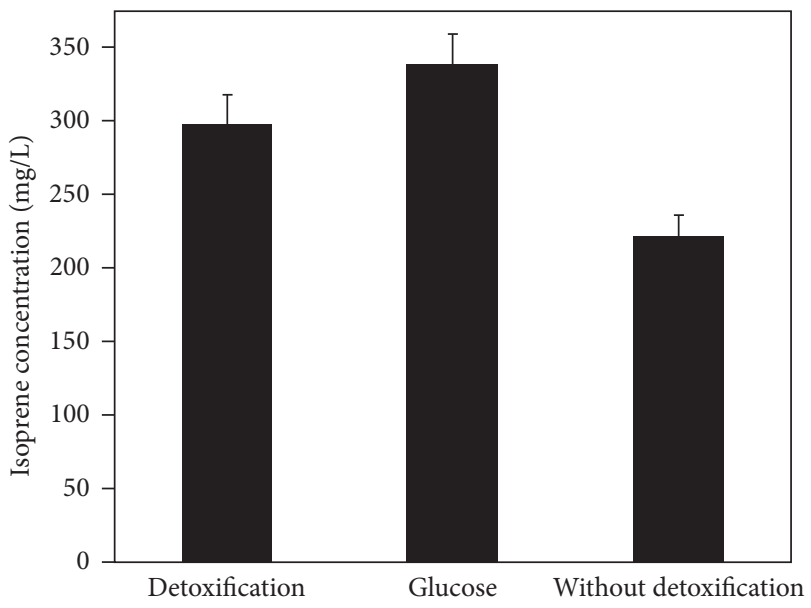

FIGURE 6: Detoxification effect of enzymatic hydrolysate of peanut hull on isoprene production. When $\mathrm{OD}_{600}$ reaches $0.6-0.9$, cultures were induced at $30^{\circ} \mathrm{C}$ for $24 \mathrm{~h}$ using $0.5 \mathrm{mM}$ IPTG. All the experiments were carried out in triplicate.

inhibitors, especially acetic acid in enzymatic hydrolysates of peanut hull, were inhibitory to engineering $E$. coli, and the removal of inhibitors from fermentation medium consequently led to a remarkable increase in the isoprene production.

3.5. The Difference in Gas Composition and Concentration between Glucose and Enzymatic Hydrolysis. To detect the variation of gas composition by different carbon sources during fermentation, the engineered strain YJM21 was cultured in the fermentation medium containing pure glucose or enzymatic hydrolysate with HPAC pretreatment as the carbon source. As shown in Figure 7 and Table 2, the gas composition 


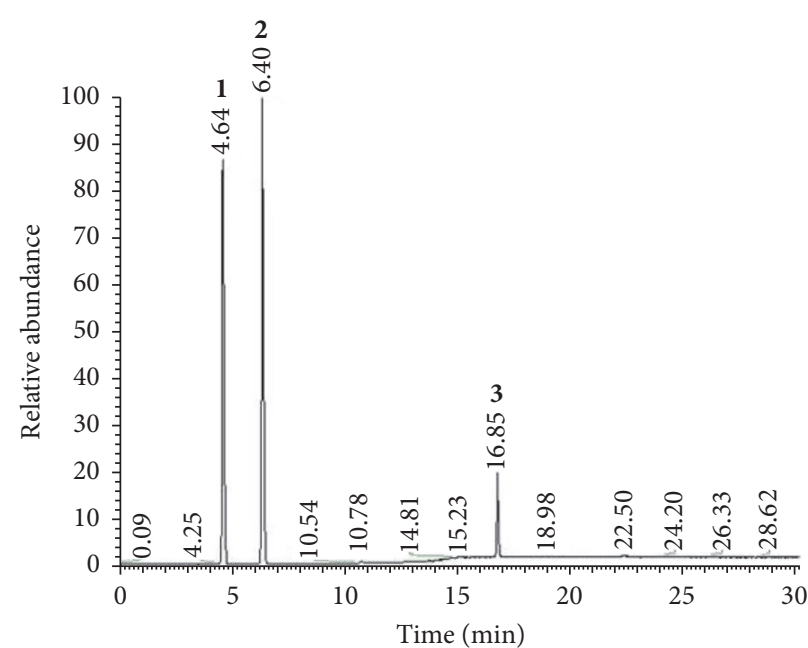

(a)

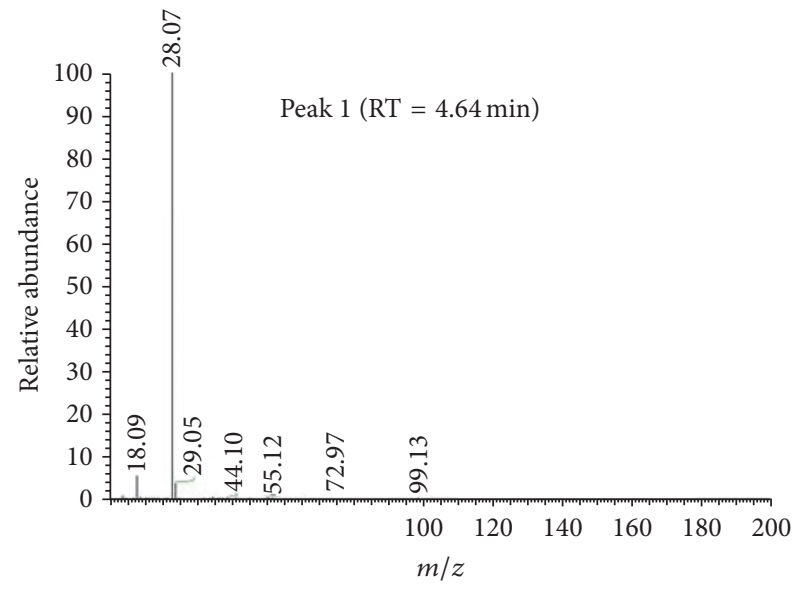

(c)

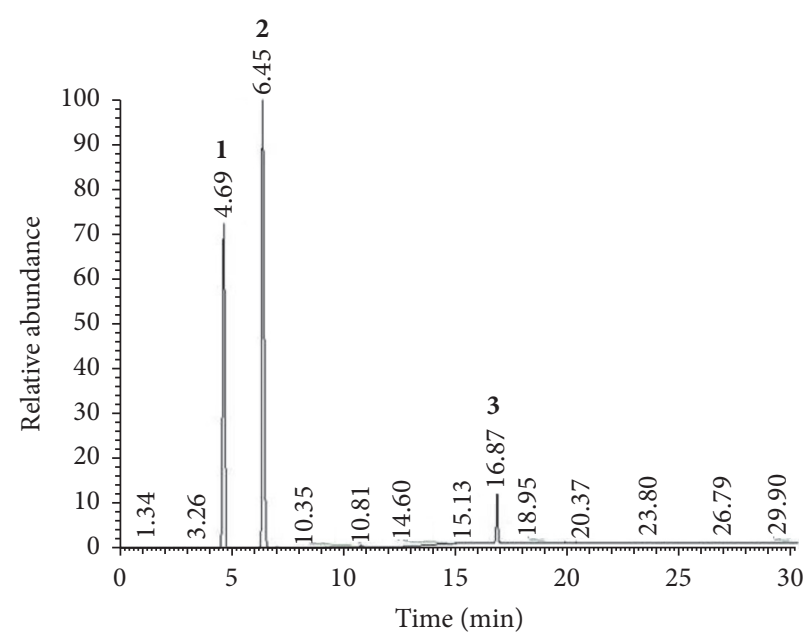

(b)

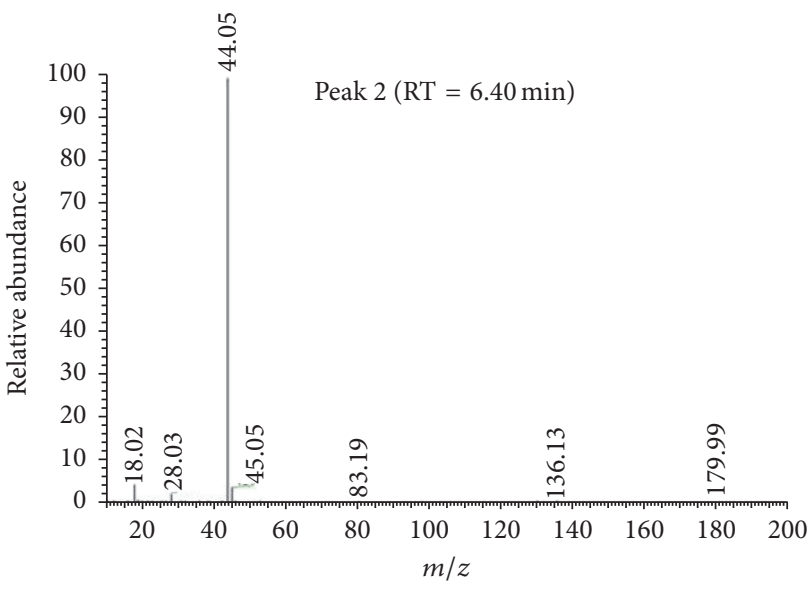

(d)

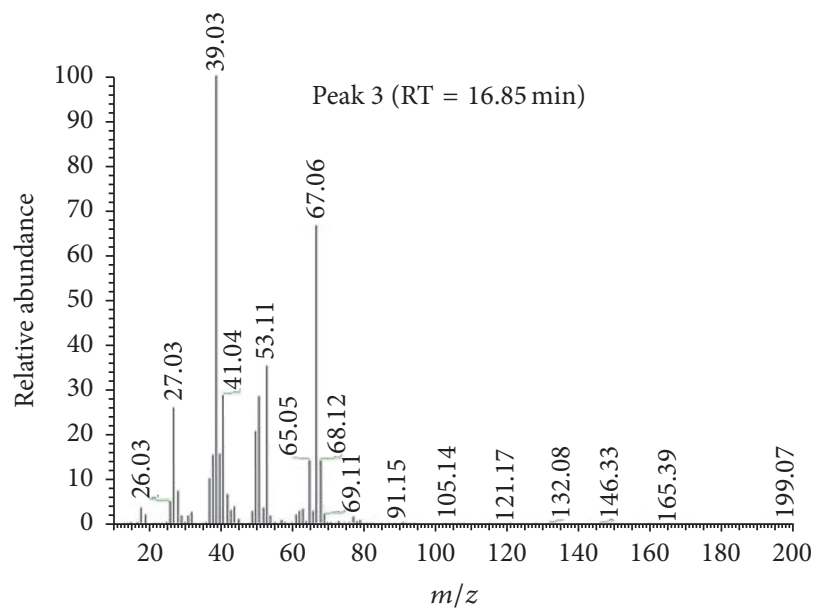

(e)

FIGURE 7: GC-MS analysis of fermentation gases. (a) GC map of gases composition of fermentation on glucose; (b) GC map of gases composition of fermentation on HPAC enzymatic hydrolysate; (c) MS map of peak $1\left(\mathrm{~N}_{2}\right)$; (d) MS map of peak $2\left(\mathrm{CO}_{2}\right)$; (e) MS map of peak 3 (isoprene). 
TABLE 2: Effect of different carbon sources on concentration of different fermentation gases.

\begin{tabular}{lccc}
\hline Gas composition (\%) & Glucose & HPAC enzymatic hydrolysate & Retention time (min) \\
\hline $\mathrm{N}_{2}$ & 42.13 & 39.34 & 4.69 \\
$\mathrm{CO}_{2}$ & 48.66 & 54.41 & 6.45 \\
Unknown gas 1 & 0.24 & 0.19 & 10.78 \\
Unknown gas 2 & 0.17 & 0.10 & 15.13 \\
Isoprene & 8.8 & 5.96 & 16.87 \\
\hline
\end{tabular}

produced by pure glucose or enzymatic hydrolysis of peanut shell remained the same, while the gas concentration turned out to be different. The gas composition consisted of $\mathrm{N}_{2}$, isoprene, $\mathrm{CO}_{2}$, and a small amount of unknown gas. $\mathrm{N}_{2}$, $\mathrm{CO}_{2}$, isoprene, and the unknown gas which were produced by pure glucose accounted for $42.13 \%, 48.66 \%, 8.8 \%$, and $0.41 \%$ of all gases, respectively, while those gases produced by enzymatic hydrolysate accounted for $39.34 \%, 54.41 \%, 5.96 \%$, and $0.29 \%$, respectively. The results indicated that though the fermentation medium constituted by enzymatic hydrolysate of peanut shell had no impact on the categories of gas composition, it could reduce the concentration of isoprene and increase the content of $\mathrm{CO}_{2}$ in the whole fermented gases.

\section{Conclusions}

Peanut hull proves to be a promising feedstock to produce bio-based chemicals and biofuels due to its easy availability and polysaccharide content characteristics. In this study, the use of peanut hull for isoprene production was explored. Two pretreatment methods, HPAC and popping, were carried out prior to enzymatic hydrolysis, which could destroy the lignocellulosic biomass structure. The isoprene production using HPAC pretreatment was found to be about 1.9 -fold higher than that using popping pretreatment. To further increase the isoprene yield, the enzymatic hydrolysate of HPAC was detoxified by activated carbon. The engineered strain YJM21 fermented on the detoxified enzymatic hydrolysate could accumulate $297.5 \mathrm{mg} / \mathrm{L}$ isoprene, which accounted for about $90 \%$ of isoprene production by YJM21 fermented on pure glucose $(338.6 \mathrm{mg} / \mathrm{L})$. This work is considered to be the first attempt to produce isoprene by $E$. coli using peanut hull as the feedstock, and it also provides evidence that another lignocellulose material, peanut hull, could be regarded as a promising feedstock for bio-based chemicals or biofuels of industrial production.

\section{Competing Interests}

The authors declare that they have no competing interests.

\section{Acknowledgments}

This work was financially supported by the Natural Science Foundation of Shandong Province, China (Grant no. ZR2015BM021), the National Natural Science Foundation of China (Grant no. 21572242), the Project of Science and
Technology for People's Livelihood of Qingdao (no. 15-9-294-nsh), the special project of science and technology development for construction (Grant no. JK2015-22), the Talents of High Level Scientific Research Foundation (Grant no. 6631113326) of Qingdao Agricultural University, the National Natural Science Foundation of China (Grant no. 31300599), the Talents of High Level Scientific Research Foundation (Grant no. 6631113318) of Qingdao Agricultural University, and the National Natural Science Foundation of China (Grant no. 31172012/c1506).

\section{References}

[1] G. A. Alianell, F. Derwitsch, D. Wells, and T. Taylor, "Isoprene compositions and methods of use," Google Patents, 2009.

[2] P. Lindberg, S. Park, and A. Melis, "Engineering a platform for photosynthetic isoprene production in cyanobacteria, using Synechocystis as the model organism," Metabolic Engineering, vol. 12, no. 1, pp. 70-79, 2010.

[3] J. Kesselmeier and M. Staudt, "Biogenic volatile organic compounds (VOC): an overview on emission, physiology and ecology," Journal of Atmospheric Chemistry, vol. 33, no. 1, pp. 2388, 1999.

[4] J. Yang, G. Zhao, Y. Sun et al., "Bio-isoprene production using exogenous MVA pathway and isoprene synthase in Escherichia coli," Bioresource Technology, vol. 104, pp. 642-647, 2012.

[5] T. D. Sharkey, S. Yeh, A. E. Wiberley, T. G. Falbel, D. Gong, and D. E. Fernandez, "Evolution of the isoprene biosynthetic pathway in kudzu," Plant Physiology, vol. 137, no. 2, pp. 700-712, 2005.

[6] J. Berenguer, V. Calderon, M. Herce, and J. Sanchez, "Spoilage of a bakery product (sobao pasiego) by isoprene-producing molds," Revista de Agroquimica y Tecnologia de Alimentos, vol. 31, pp. 580-583, 1991.

[7] A. Melis, "Solar energy conversion efficiencies in photosynthesis: minimizing the chlorophyll antennae to maximize efficiency," Plant Science, vol. 177, no. 4, pp. 272-280, 2009.

[8] P. Sassner, C.-G. Mårtensson, M. Galbe, and G. Zacchi, "Steam pretreatment of $\mathrm{H}_{2} \mathrm{SO}_{4}$-impregnated Salix for the production of bioethanol," Bioresource Technology, vol. 99, no. 1, pp. 137-145, 2008.

[9] C. Pothiraj, A. Arun, and M. Eyini, "Simultaneous saccharification and fermentation of cassava waste for ethanol production," Biofuel Research Journal, vol. 2, no. 1, pp. 196-202, 2015.

[10] Ministry of Agriculture of the People's Republic of China, Law and Regulations, 2009.

[11] United States Department of Agriculture (USDA), http:// ndb.nal.usda.gov/ndb/foods/show $/ 4800$ ? fgcd $=\& m a n u=\& l f a c-$ et $=\&$ format $=\&$ count $=\& \max =35 \&$ offset $=\&$ sort $=\& q$ lookup $=$ pea nut. 
[12] N. Mosier, C. Wyman, B. Dale et al., "Features of promising technologies for pretreatment of lignocellulosic biomass," Bioresource Technology, vol. 96, no. 6, pp. 673-686, 2005.

[13] I. S. Choi, S. G. Wi, S.-B. Kim, and H.-J. Bae, "Conversion of coffee residue waste into bioethanol with using popping pretreatment," Bioresource Technology, vol. 125, pp. 132-137, 2012.

[14] S. G. Wi, I. S. Choi, K. H. Kim, H. M. Kim, and H.-J. Bae, "Bioethanol production from rice straw by popping pretreatment," Biotechnology for Biofuels, vol. 6, no. 1, article 166, 2013.

[15] G. Banerjee, S. Car, T. Liu et al., "Scale-up and integration of alkaline hydrogen peroxide pretreatment, enzymatic hydrolysis, and ethanolic fermentation," Biotechnology and Bioengineering, vol. 109, no. 4, pp. 922-931, 2012.

[16] S. C. Rabelo, R. R. Andrade, R. Maciel Filho, and A. C. Costa, "Alkaline hydrogen peroxide pretreatment, enzymatic hydrolysis and fermentation of sugarcane bagasse to ethanol," Fuel, vol. 136, pp. 349-357, 2014.

[17] S. G. Wi, B. Y. Chung, Y. G. Lee, D. J. Yang, and H.-J. Bae, "Enhanced enzymatic hydrolysis of rapeseed straw by popping pretreatment for bioethanol production," Bioresource Technology, vol. 102, no. 10, pp. 5788-5793, 2011.

[18] S. G. Wi, E. J. Cho, D.-S. Lee, S. J. Lee, Y. J. Lee, and H.-J. Bae, "Lignocellulose conversion for biofuel: a new pretreatment greatly improves downstream biocatalytic hydrolysis of various lignocellulosic materials," Biotechnology for Biofuels, vol. 8, article 228, 2015.

[19] A. Sluiter, B. Hames, R. Ruiz et al., "Determination of structural carbohydrates and lignin in biomass," Tech. Rep. N TP-51042618 2011:17, National Renewable Energy Laboratory, Golden, Colo, USA, 2010.

[20] TAPPI Standard, Solvent Extractives of Wood and Pulp, TAPPI, 1997.

[21] J. Yang, M. Xian, S. Su et al., "Enhancing production of bioisoprene using hybrid MVA pathway and isoprene synthase in E. coli," PLoS ONE, vol. 7, no. 4, Article ID e33509, 2012.

[22] Y. Zhao, J. Yang, B. Qin et al., "Biosynthesis of isoprene in Escherichia coli via methylerythritol phosphate (MEP) pathway," Applied Microbiology and Biotechnology, vol. 90, no. 6, pp. 1915-1922, 2011.

[23] J. Xue and B. K. Ahring, "Enhancing isoprene production by genetic modification of the 1-deoxy-D-Xylulose-5-phosphate pathway in Bacillus subtilis," Applied and Environmental Microbiology, vol. 77, no. 7, pp. 2399-2405, 2011.

[24] S.-Y. Hong, A. S. Zurbriggen, and A. Melis, "Isoprene hydrocarbons production upon heterologous transformation of Saccharomyces cerevisiae," Journal of Applied Microbiology, vol. 113, no. 1, pp. 52-65, 2012.

[25] R. M. Rowell, Handbook of Wood Chemistry and Wood Composites, CRC Press, New York, NY, USA, 2012.

[26] M. Galbe and G. Zacchi, "Pretreatment of lignocellulosic materials for efficient bioethanol production," in Biofuels, L. Olsson, Ed., vol. 108 of Advances in Biochemical Engineering/Biotechnology, pp. 41-65, Springer, 2007.

[27] L. J. Jönsson, B. Alriksson, and N.-O. Nilvebrant, "Bioconversion of lignocellulose: inhibitors and detoxification," Biotechnology for Biofuels, vol. 6, no. 1, article 16, 2013.

[28] A. K. Chandel, S. S. da Silva, and O. V. Singh, "Detoxification of lignocellulose hydrolysates: biochemical and metabolic engineering toward white biotechnology," BioEnergy Research, vol. 6, no. 1, pp. 388-401, 2013.
[29] E. Palmqvist and B. Hahn-Hägerdal, "Fermentation of lignocellulosic hydrolysates. II: inhibitors and mechanisms of inhibition," Bioresource Technology, vol. 74, no. 1, pp. 25-33, 2000.

[30] T. Y. Mills, N. R. Sandoval, and R. T. Gill, "Cellulosic hydrolysate toxicity and tolerance mechanisms in Escherichia coli," Biotechnology for Biofuels, vol. 2, no. 1, article 26, 2009.

[31] A. Martinez, M. E. Rodriguez, S. W. York, J. F. Preston, and L. O. Ingram, "Effects of $\mathrm{Ca}(\mathrm{OH})_{2}$ treatments ('overliming') on the composition and toxicity of bagasse hemicellulose hydrolysates," Biotechnology and Bioengineering, vol. 69, no. 5, pp. 526-536, 2000.

[32] R. E. Berson, J. S. Young, S. N. Kamer, and T. R. Hanley, "Detoxification of actual pretreated corn stover hydrolysate using activated carbon powder," Applied Biochemistry and Biotechnology, vol. 124, no. 1, pp. 923-934, 2005.

[33] W. Parawira and M. Tekere, "Biotechnological strategies to overcome inhibitors in lignocellulose hydrolysates for ethanol production: review," Critical Reviews in Biotechnology, vol. 31, no. 1, pp. 20-31, 2011. 

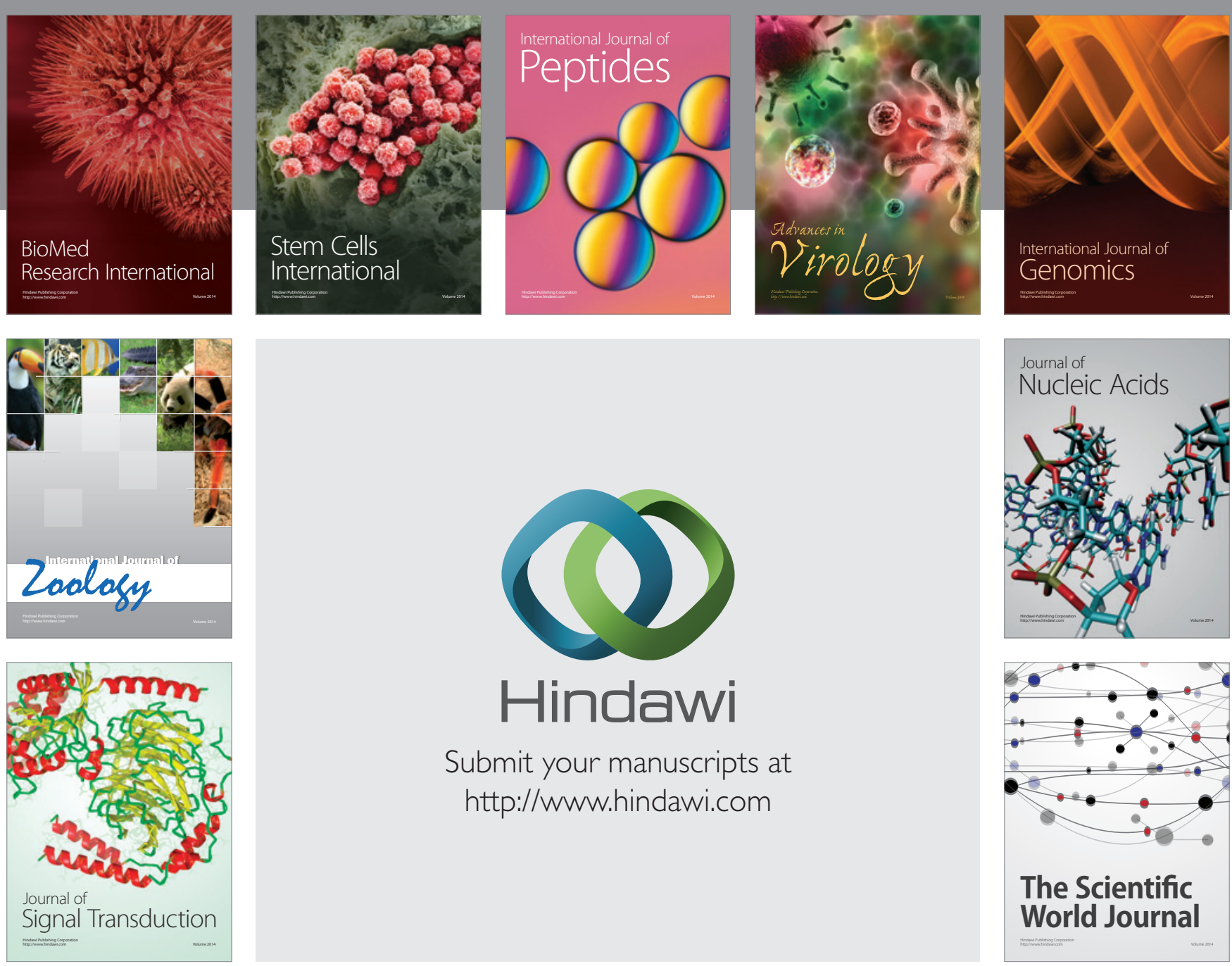

Submit your manuscripts at

http://www.hindawi.com
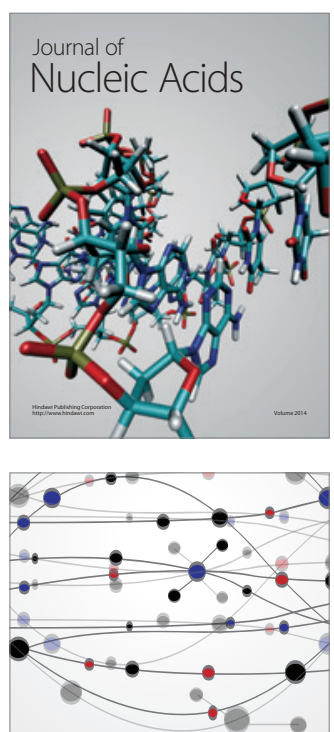

The Scientific World Journal
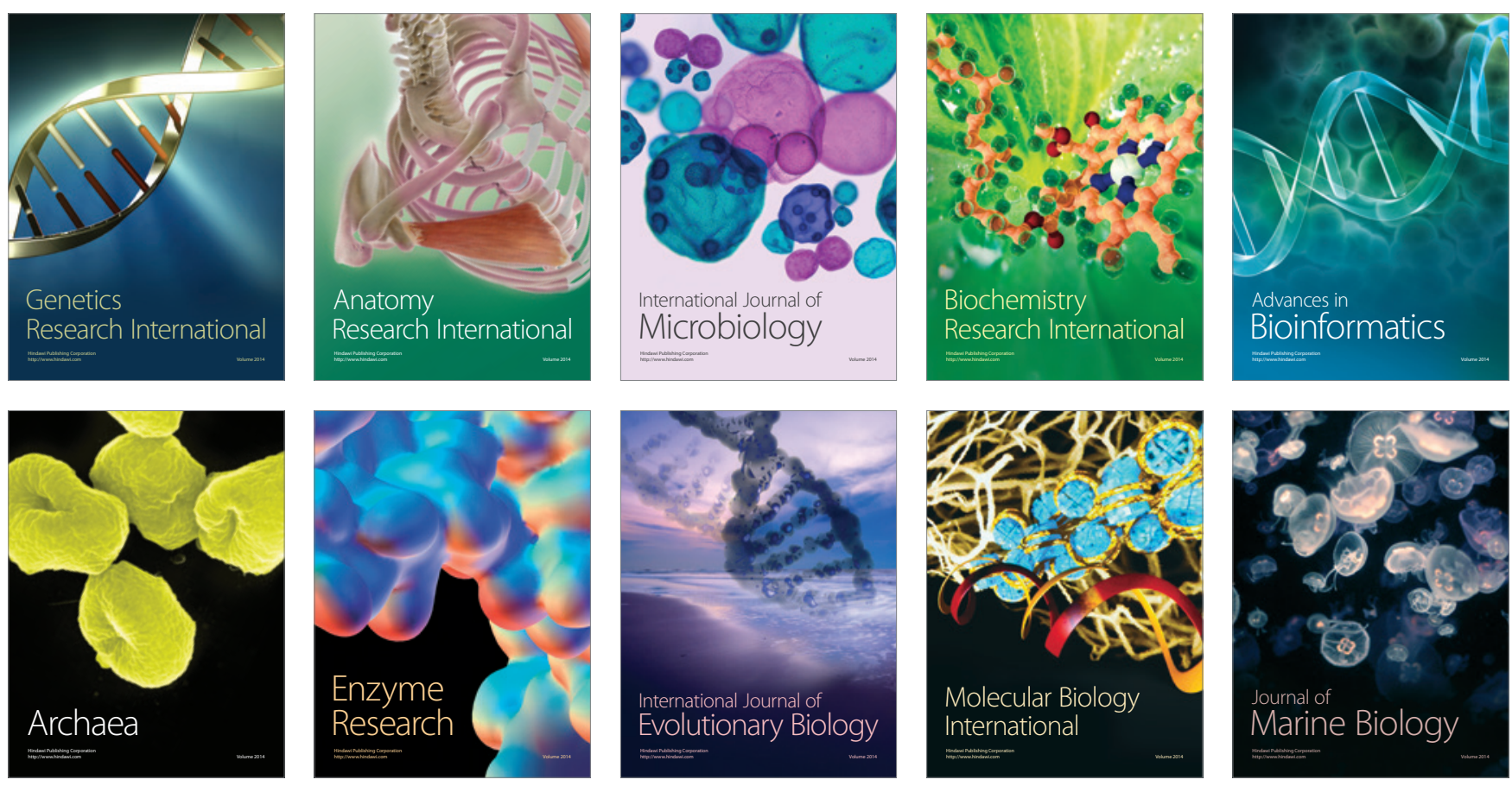